\title{
Role of exteroceptive background context in taste-aversion conditioning and extinction
}

\author{
TREVOR ARCHER, PER-OLOW SJÖDÉN, LARS-GÖRAN NILSSON \\ and NED CARTER \\ University of Uppsala, S-751 04 Uppsala, Sweden
}

\begin{abstract}
In two experiments, saccharin (CS) and lithium chloride (US) were paired in a context consisting of specific visual, auditory, tactual, and olfactory cues. The saccharin aversion was then extinguished in a context free from conditioning-context cues. Later, saccharin preference tests were given in the presence and absence of these cues. The results indicated that the background cues of the conditioning trial controlled the amount of saccharin drunk on extinction trials, and, furthermore, that extinction of the taste aversion was context specific; i.e., groups given extinction trials in a different (from conditioning) context retained their saccharin aversion in the conditioning context only. The results indicate an important role played by the exteroceptive context in taste-aversion conditioning.
\end{abstract}

In studies of taste-aversion learning using rats as subjects, a general finding has been that associations between exteroceptive events and nausea are difficult to establish, at least in comparison to taste-nausea associations (Garcia, Kimeldorf, \& Hunt, 1961; Garcia \& Koelling, 1966; Green, Holmstrom, \& Wollman, 1974). Thus, when exteroceptive cues have been paired with illness, subsequent water intake in the presence of these cues has been suppressed very little (Domjan \& Wilson, 1972; Garcia \& Koelling, 1967; Garcia, McGowan, Ervin, \& Koelling, 1968). The finding of an unequal associability between classes of events (the "Garcia effect") has prompted a variety of theoretical formulations, centering on the idea that the evolutionary history of a particular species determines the relative associability of events for members of that species (e.g., Rozin \& Kalat, 1972; Seligman, 1970). Thus, Seligman's (1970) prepared learning theory states: "Rats are prepared, by virtue of their evolutionary history, to associate tastes with malaise.... Further, rats are contraprepared to associate exteroceptive events with nausea" (p. 409). Several other workers have likewise emphasized the unique importance of the association of the taste and the gastrointestinal events of nausea in taste-aversion learning (Revusky \& Garcia, 1970; Rozin \& Kalat, 1971).

In the above studies, the main interest has been to investigate the relative roles of interoceptive and

\footnotetext{
Thanks are due to $\mathrm{R}$. Karlsson for assistance with data treatment, and to G. Ohlin for animal caretaking. Valuable comments were contributed by B. Andersson and T. U. C. Järbe. The present research was supported by grants from the University of Uppsala. Reprints may be obtained from Dr. P. O. Sjödén, Department of Psychology, Uppsala University, P. O. Box 227, S-751 04 Uppsala, Sweden.
}

exteroceptive stimuli in aversion-learning in general. Thus, in studies of exteroceptive control of aversions, attempts have been made to produce aversions to exteroceptive cues in the absence of a taste stimulus (e.g., Larsen \& Hyde, 1977). It could be argued that the question of the role of exteroceptive stimuli in taste-aversion learning has not been addressed by the above studies. However, a wide-spread assumption held by many workers seems to be that such stimuli are of no importance in taste-aversion learning (e.g., Revusky \& Garcia, 1970; Rozin \& Kalat, 1971).

The discovery of the "Garcia effect" (Garcia \& Koelling, 1966) prompted not only a rise in neoevolutionary accounts of learning, but also purportedly discredited a 'general process' view (Seligman, 1970). The latter approach implied that different classes of stimuli were equipotential with respect to associability. However, Revusky (1977) has recently argued that a "general process" view of learning can account for most empirical phenomena pertaining to tasteaversion learning. Following this line of argument, it would seem profitable to take "general process" theories of learning as a starting point in taste-aversion studies, and to subject predictions from such theories to empirical scrutiny. In some recent theories of conditioning (e.g., Estes, 1973; Rescorla \& Wagner, 1972), an important role has been assigned to the exteroceptive background context in which the CS-US pairing takes place. From this notion, it can be predicted that a change of exteroceptive context from the conditioning to, for example, an extinction phase would lead to a weaker CR than if the conditioning context was maintained. Also, extinguishing the $C R$ in a context different from the conditioning context would affect the $C R$ in the conditioning context very little. When applied to taste-aversion conditioning, the above predictions contrast sharply 
with the notion suggested above that exteroceptive stimuli can be ignored in this learning paradigm.

It should be noted that some investigators have succeeded in producing aversions to exteroceptive cues (Best, Best, \& Mickley, 1973; Mitchell, Kirschbaum, \& Perry, 1975; Rozin, 1969). Also, in two studies, the importance of exteroceptive stimulation for taste- and illness-familiarity effects in tasteaversion learning has been demonstrated (Rudy, Iwens, \& Best, 1977; Rudy, Rosenberg, \& Sandell, 1977). Thus, further context-specific effects in tasteaversion learning are to be expected.

\section{EXPERIMENT 1}

Experiment 1 was intended as an investigation of whether or not the exteroceptive background context of the conditioning trial controlled the degree of saccharin aversion during subsequent extinction trials. This was tested by presenting saccharin during extinction either in the same context as that of conditioning or in a different exteroceptive context. In order to study whether or not the extinction of the saccharin aversion was context specific, subsequent preference tests, pitting saccharin against water, were performed in both contexts.

\section{Method}

The subjects were 24 experimentally naive male Sprague-Dawley rats (AB Anticimex, Sollentuna, Sweden), with a mean body weight of $225 \mathrm{~g}$ at the beginning of the experiment. They were assigned to four groups $(n=6)$, matched for body weight. The animals were kept on a 12-h-on/12-h-off lighting schedule (lights on at $0800 \mathrm{~h}$ ) in a room maintained between $21^{\circ}$ and $23^{\circ} \mathrm{C}$. Food (lab chow R3, Astra-Ewos, Sodertälje, Sweden) was available ad lib. Water, presented in glass bottles with metal nozzles that had a 2-mm opening at the tip ("silent" bottles, see below), was freely available during an acclimatization period of 2 weeks. After that, the animals were trained for 6 days to take fluid on a $30 \mathrm{~min} /$ day drinking schedule, by limiting their drinking period first to 60 and then to $30 \mathrm{~min} /$ day. By the end of this training, they were offered water from 1400 to $1430 \mathrm{~h}$ only. All subsequent fluid exposures (except preference tests) took place at these hours. During the acclimatization period, the animals were housed in individual Perspex cages $(16.5 \times 22.5 \times 13.5 \mathrm{~cm})$ with metal grid covers with spaces for food and a water bottle. During the $30 \mathrm{~min} /$ day drinking training (preconditioning, see Table 1), they were placed in individual compartments $(15 \times 35 \times 20 \mathrm{~cm})$ ("contextual" compartments, see below). These compartments were opaque plastic boxes, in which a thin layer of Vicks ointment (Vicks Vapo Rub, Richardson-Merrell, London) was smeared on one inner wall every 2 days to give a distinct odor cue. Except for two small holes for the drinking bottles, light was excluded from the compartments by Masonite covers. Food pellets were placed on the floor of the compartments. Thus, during the preconditioning period, the rats were housed under environmental conditions characterized by the Vicks odor, opaque walls, darkness, and food presented on the floor. In addition, water was offered in "noisy" bottles with metal nozzles that had a 6-mm hole at the tip and contained a small metal ball to minimize leakage. These bottles, which were present only in "contextual" compartments, created considerable noise when the animals licked the top of the nozzles, causing the balls to bounce up and down.

Experimental conditions and treatments are outlined in Table 1. On Day 1 (taste-aversion conditioning), all animals were returned to their normal cages. After that, they were offered a $.2 \%$ saccharin solution in "silent" bottles for $30 \mathrm{~min}$, followed, after an interval of approximately $20 \mathrm{~min}$, by a lithium chloride $(\mathrm{LiCl})$ or a saline $(\mathrm{NaCl})$ injection. Groups 2D (two conditioning trials, context during extinction phase different from conditioning), $2 S$ (two trials, context during extinction same as conditioning), and 2DW (two trials, drinking water only during the extinction phase in a context different from that of conditioning), received a $2.5-\mathrm{ml}$ intraperitoneal injection of $\mathrm{LiCl}(.15 \mathrm{M})$, while Group 2DC (control group, different context during extinction phase) received an identical volume of sterile $\mathrm{NaCl}(.11 \mathrm{M})$. The identical procedure was followed on Day 2. On Day 3 (Extinction 1: $E_{1}$ ), Groups $2 \mathrm{D}, 2 \mathrm{DC}$, and $2 \mathrm{DW}$ were returned to their "contextual" compartments while Group $2 S$ remained in their normal cages. The $2 \mathrm{~S}$ animals were handled in order to equate the handling received by all groups. Groups 2D, 2S, and 2DC then were offered a $.2 \%$ saccharin solution for $30 \mathrm{~min}$, while Group $2 \mathrm{DW}$ was offered water. Identical saccharin/water presentations were made on Days 4-7 $\left(E_{2}-E_{5}\right)$. On Day 8 (Test 1:T $T_{1}$ ), Groups $2 D, 2 D C$, and 2DW were returned to their normal cages, while Group 2S, remaining in normal cages, was only handled. After placement in normal cages, all groups were given an 8 -h satcharin preference test $(1200$ to $2000 \mathrm{~h})$, each animal receiving one saccharin $(.2 \%)$ bottle and one water bottle of the "silent" kind. A second preference test $\left(T_{2}\right)$ followed on Day 9. On Day 10, all animals were moved to the "contextual" compartments, where they received a

Table 1

Experimental Treatments and Chronology

\begin{tabular}{|c|c|c|c|c|c|}
\hline \multirow[b]{2}{*}{ Group } & \multicolumn{2}{|c|}{ Conditioning } & \multirow{2}{*}{$\begin{array}{c}\text { Extinction } \\
\text { Days 3-7 }\end{array}$} & \multicolumn{2}{|c|}{ Preference Tests } \\
\hline & Day 1 & Day 2 & & Days 8-9 & Day 10 \\
\hline \multicolumn{6}{|c|}{ Experiment 1 (Contextual Preconditioning) } \\
\hline $\begin{array}{l}2 \mathrm{D} \\
2 \mathrm{~S} \\
2 \mathrm{DC} \\
2 \mathrm{DW}\end{array}$ & $\begin{array}{l}\text { Normal, Saccharin + } \mathrm{LiCl} \\
\text { Normal, Saccharin + LiCl } \\
\text { Normal, Saccharin + NaCl } \\
\text { Normal, Saccharin + LiCl }\end{array}$ & $\begin{array}{l}\text { Normal, Saccharin + LiCl } \\
\text { Normal, Saccharin + LiCl } \\
\text { Normal, Saccharin + NaCl } \\
\text { Normal, Saccharin + LiCl }\end{array}$ & $\begin{array}{l}\text { Contextual, Saccharin } \\
\text { Normal, Saccharin } \\
\text { Contextual, Saccharin } \\
\text { Contextual, Water }\end{array}$ & $\begin{array}{l}\text { Normal } \\
\text { Normal } \\
\text { Normal } \\
\text { Normal }\end{array}$ & $\begin{array}{l}\text { Contextual } \\
\text { Contextual } \\
\text { Contextual } \\
\text { Contextual }\end{array}$ \\
\hline \multicolumn{6}{|c|}{ Experiment 2 (Normal Preconditioning) } \\
\hline $\begin{array}{ll}2 & \mathrm{D} \\
1 \mathrm{D} \\
2 \mathrm{~S} \\
1 \mathrm{~S}\end{array}$ & $\begin{array}{l}\text { Contextual, Saccharin }+\mathrm{LiCl} \\
\text { Normal, Water } \\
\text { Contextual, Saccharin }+\mathrm{LiCl} \\
\text { Normal, Water }\end{array}$ & $\begin{array}{l}\text { Contextual, Saccharin }+\mathrm{LiCl} \\
\text { Contextual, Saccharin }+\mathrm{LiCl} \\
\text { Contextual, Saccharin }+\mathrm{LiCl} \\
\text { Contextual, Saccharin }+\mathrm{LiCl}\end{array}$ & $\begin{array}{l}\text { Normal, Saccharin } \\
\text { Normal, Saccharin } \\
\text { Contextual, Saccharin } \\
\text { Contextual, Saccharin } \\
\end{array}$ & $\begin{array}{l}\text { Contextual } \\
\text { Contextual } \\
\text { Contextual } \\
\text { Contextual } \\
\end{array}$ & $\begin{array}{l}\text { Normal } \\
\text { Normal } \\
\text { Normal } \\
\text { Normal }\end{array}$ \\
\hline
\end{tabular}

Note-The following abbreviations are used for describing groups: $D=$ extinction context different from conditioning context; $S=$ extinction and conditioning contexts the same; $C=$ control; $W=$ water during extinction phase. The numerals 1 and 2 indicate the number of conditioning trials. 
third preference test $\left(\mathrm{T}_{3}\right)$ with fluids offered in the "noisy" bottles. The percent preference for saccharin was computed as: (saccharin intake/saccharin intake + water intake) $\times 100$. Throughout, fluid intake was recorded by weighing the bottles to the nearest $1.0 \mathrm{~g}$.

\section{Results and Discussion}

All data were subjected to analysis of variance (Kirk, 1968), based on either completely randomized or split-plot designs, with the .05 level of significance adopted throughout. Testing of pairwise differences between groups was performed with the Tukey HSD test, with $\mathrm{p}<.01$.

There were no significant differences between groups with respect to the amount of saccharin consumed on the first exposure, mean values for saccharin intake on Day 1 being: Group 2D, $11.3 \mathrm{~g}$; Group 2S, $9.2 \mathrm{~g}$; Group 2DC, $11.0 \mathrm{~g}$; and Group 2DW, $10.8 \mathrm{~g}$. An analysis of Day 2 data indicated that the control group (2DC) drank significantly more saccharin than the remaining groups: $2 \mathrm{D}, 5.5 \mathrm{~g} ; 2 \mathrm{~S}, 3.5 \mathrm{~g} ; 2 \mathrm{DC}$, $14.2 \mathrm{~g}$; and $2 \mathrm{DW}, 3.2 \mathrm{~g}$, resulting in a significant groups effect $[F(3,20)=26.2]$. Thus, saccharin aversions were reliably produced in all experimental groups.

The data from the extinction phase $\left(E_{1}-E_{s}\right)$ on Days 3-7 indicate that the background cues of the conditioning phase exerted considerable control over the amount of saccharin drunk during the extinction phase (see Figure 1, left-hand panel). An analysis of variance revealed a Groups by Days interaction $[F(12,80)=2.4]$. Subsequent pairwise analyses showed a significantly lower saccharin intake in Group $2 S$ as compared to all other groups on all extinction days, and a lower saccharin intake in Group 2D as compared to Groups 2DC (saccharin) and $2 \mathrm{DW}$ (water) for $\mathrm{E}_{1}$. Thus, the presence of the conditioning-context cues for Group 2S suppressed saccharin intake significantly during the entire extinction phase. However, when the conditioning context was replaced by another context (Group 2D), a suppressive effect of the conditioning trials on saccharin intake was seen only on the first extinction day.

The preference test data (see Figure 1, right-hand panel) indicated that extinction of the saccharin aversion in a context different from that of the conditioning trials (Group 2D) did not result in a decrease of the aversion in the conditioning context $\left(T_{1}\right.$ and $\left.T_{2}\right)$. However, reinstatement of the extinction context for Group 2D on $T_{3}$ yielded no evidence of a saccharin aversion. Thus, there was a Groups by Tests interaction $[F(6,40)=27.5]$. Pairwise comparisons revealed the following differences. For $T_{1}$ and $T_{2}$, when the conditioning context was reinstated for the D groups, Groups 2D and 2DW showed more saccharin aversion than Groups $2 \mathrm{~S}$ and 2DC. Also, $2 \mathrm{~S}$ showed more saccharin aversion than $2 \mathrm{DC}$. These

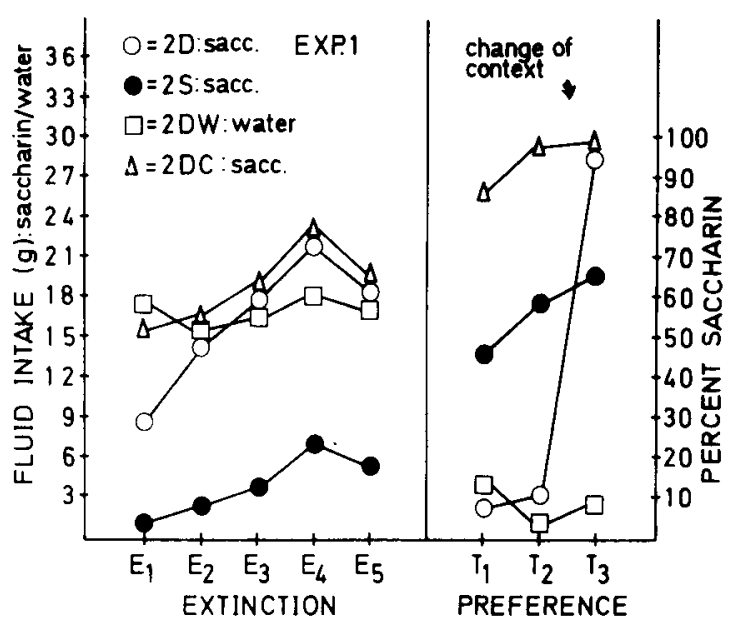

Figure 1. Results of Experiment 1 (see text).

results indicate that reinstatement of the conditioning context for Group 2D produced as strong an aversion as was found in the group (2DW) for which water only was present during the extinction phase. Also, a stronger aversion was evident in Group 2D than in the group (2S) which had consumed saccharin in the conditioning context during the extinction phase. The observation that the aversion remained stronger in Group 2S as compared to Group 2DC indicates that five extinction trials were insufficient to completely extinguish the aversion in Group $2 \mathrm{~S}$.

For $T_{3}$, when the extinction context was reintroduced for all groups, Groups 2S and 2DW showed a higher degree of aversion than Groups 2D and 2DC. This indicates context-specific extinction of the aversion in Group 2D, as shown by the 2D-2DW difference (note also the dramatic increase from $T_{2}$ to $T_{3}$ for Group 2D). The 2S-2DC difference again substantiates the incomplete extinction in the $2 \mathrm{~S}$ group.

\section{EXPERIMENT 2}

The rationale of Experiment 2 was twofold. First, in Experiment 1 all groups were in the presence of a set of distinctive contextual cues during the preconditioning phase (see Table 1), and these cues were used as the extinction context for the D groups. The conditioning background context was defined by an absence of these particular cues for all groups, i.e., replacement in standard laboratory cages. Thus, it is of interest to replicate the design of Experiment 1, using the distinctive contextual cues as the conditioning background context and the standard cage environment as the "different" context. Secondly, as is evident from the data of Experiment 1, the saccharin aversion of Group $2 S$ was only incompletely extinguished by the end of the extinction phase. This may be due to the use of two conditioning trials, which may require a greater number of extinction 
trials for the aversion to be abolished. Preferably, all groups should evidence a similar amount of saccharin intake by $E_{5}$, in order to optimize the conditions for observing context-dependent effects on the preference tests. Thus, Experiment 2 examined the effects of one vs. two conditioning trials.

\section{Method}

The subjects were 24 experimentally naive male Sprague-Dawley rats, weighing approximately $225 \mathrm{~g}$ at the beginning of the experiment. They were assigned to four groups $(n=6)$, matched for body weight. The acclimatization procedure was carried out as in Experiment 1. During the preconditioning period (see Table 1), all animals were accustomed to water access between 1400 and $1430 \mathrm{~h}$ in their normal cages with "silent" bottles. Experimental treatments and conditions are summarized in Table 1. Injections, cages/compartments, handling, and extinction and preference tests were carried out as in Experiment 1, with the exceptions noted below.

On Day 1, Groups 2D and 2S were moved to the "contextual" compartments and were given one conditioning trial; Groups 1D and $1 \mathrm{~S}$ remained in normal cages and were offered water. On Day 2, Groups 1D and 1S were moved to "contextual" compartments, and all groups received a saccharin- $\mathrm{LiCl}$ conditioning trial. On Day 3, Groups 2D and ID were returned to their normal cages, while Groups 2S and 1S remained in the "contextual" compartments. All animals then received a first extinction trial $\left(E_{1}\right)$ consisting of a $30-m i n$ saccharin presentation in their respective cages/compartments. On Days 4-7, Extinction Trials 2-5 $\left(E_{2}-E_{5}\right)$ were presented to all groups. On Day 8, the rats of Groups 2D and ID were returned to the "contextual" compartments and a saccharin preference test $\left(T_{1}\right)$ was given to all animals. A second preference test $\left(T_{2}\right)$ followed on Day 9 . On Day 10, all groups were returned to normal cages and a third preference test $\left(\mathrm{T}_{3}\right)$ was administered.

\section{Results and Discussion}

A comparison of saccharin intake on the first exposure-for Groups 2D (15.3 g) and 2S (10.8 g) on Day 1 and for Groups 1D (10.0 g) and 1S (9.7 g) on Day 2-revealed no significant differences. An analysis of Day 2 data involving all four groups $(2 \mathrm{D}, 5.8 \mathrm{~g} ; 2 \mathrm{~S}, 6.2 \mathrm{~g}$ ) revealed reliable conditioning in the two-trial groups $[F(3,20)=4.7]$, the Scheffé test (Kirk, 1968, p. 90) indicating a significantly lower intake $(p<.05)$ in the combined two-trial groups than in the combined one-trial groups.

The results of the extinction phase (see Figure 2, left-hand panel) indicate that, with the exception of $\mathrm{E}_{1}$, the presence of the conditioning background context was necessary to yield evidence of a saccharin aversion. Thus, the analysis of variance evidenced a significant Groups by Days interaction $[F(12,80)=$ 6.1]. Subsequent testing of pairwise differences indicated that the two-trial group remaining in the conditioning context (2S) consumed less saccharin than both groups drinking saccharin in the "different" context $(2 D, 1 D)$ for $E_{1}-E_{4}$. The one-trial group remaining in the conditioning context (1S) drank less than the "different"'-context groups (2D, 1D) for $E_{2}$ only. Thus, Experiment 2 replicated the finding of Experiment 1 for the two-trial condition, in that the

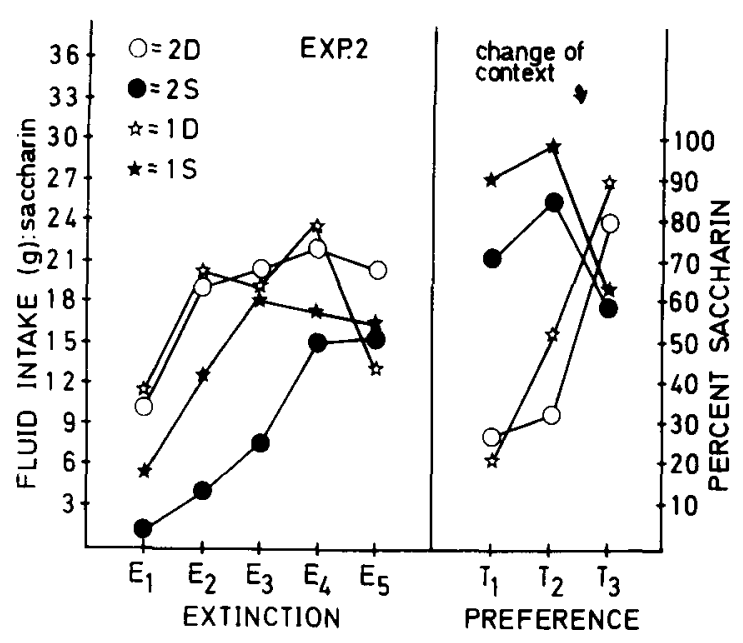

Figure 2. Results of Experiment 2 (see text).

background context of the conditioning trials was shown to control saccharin intake during extinction. Also, an identical effect was found for one conditioning trial during an intermediate stage of extinction ( $E_{2}$ only).

With respect to the differential effects of one vs. two conditioning trials, pairwise comparisons indicated that Group $2 S$ drank less saccharin than Group 1S on $E_{2}$ and $E_{3}$. No differential effects of the number of trials were observed in the $\mathrm{D}$ groups. This pattern of effects may indicate that what is learned about the aversiveness of the taste in tasteaversion conditioning is accomplished in one trial and is not further increased after two trials, since $2 \mathrm{D}=1 \mathrm{D}$ throughout. However, when differential effects of one vs. two trials are observed under normal (no change of context) conditions, these may be due to the animals learning more about the background context with the higher number of trials, since $2 S<1 S$ for $E_{2}$ and $E_{3}$. Clearly, this pattern of effects needs to be replicated before too much weight is given to it. However, it may further underline the importance of the background context in taste-aversion conditioning.

All groups achieved a very similar level of saccharin intake by $E_{5}$. However, Group ID drank significantly less than Group 2D, due to an unaccountably low intake by two animals of the former group on that particular trial.

The preference-test data (see Figure 2, right-hand panel) also confirm the results from Experiment 1 in that the groups that drank saccharin during the extinction phase in the conditioning environment (2S, 1S) showed an extinguished saccharin aversion on $T_{1}$ and $T_{2}$, which were performed in the conditioning context. However, the groups that consumed saccharin during the extinction phase in a background context different from that of conditioning (2D, 1D) demonstrated a considerable saccharin aversion on 
preference tests in the conditioning context $\left(T_{1}\right.$ and $T_{2}$ ). Thus, the analysis of variance yielded a Groups by Tests interaction $[F(6,40)=12.7]$. Subsequent pairwise testing indicated that both $\mathrm{D}$ groups showed a significantly higher degree of saccharin aversion than both $S$ groups for $T_{1}$ and $T_{2}$, with the exception that the $1 \mathrm{D}-2 \mathrm{~S}$ difference for $\mathrm{T}_{2}$ did not reach statistical significance. No differences were seen for $\mathrm{T}_{3}$, since the $\mathrm{S}$ groups were moved to a context which had never been paired with saccharin (an "irrelevant" context), and seemed to show a "neophobic" response to the taste-context combination, whereas the D groups increased their saccharin preference dramatically, since they were moved to their extinction context.

\section{GENERAL DISCUSSION}

The present results demonstrate the importance of the background context of the conditioning and extinction phases in taste-aversion learning experiments in the following ways: (1) The background context of the conditioning trial exerts a major control over the amount of saccharin consumed on subsequent one-bottle extinction tests. In fact, evidence of a saccharin aversion was obtained on Extinction Tests 2-5 only when the background context of the conditioning and extinction trials were identical. (2) The background context in which saccharin was presented during the extinction phase largely determined the degree of saccharin aversion on subsequent preference tests. In fact, when the preference tests were performed in the conditioning context, the degree of aversion shown by the group given saccharin access during the extinction phase in a context different from that of conditioning (Group 2D of Experiment 1) did not differ from that of the group presented with water only during the extinction phase (2DW of Experiment 1). However, when the preference test was performed in the extinction context, Group 2D showed no evidence of a saccharin aversion.

In general terms, the data indicate that rats, in fact, do learn about the background context as well as the taste stimulus in taste-aversion conditioning. Thus, the data directly contradict propositions implying that the animals "tend to ignore external events" (Revusky \& Garcia, 1970, p. 22; see also Garcia, McGowan, \& Green, 1972; Rozin \& Kalat, 1971) in this situation. They also contradict the recent proposition by Kalat (1977) that taste-aversion learning, in contrast to, for example, shock-avoidance learning, generalizes readily to a new environment (cf. Garcia, Kovner, \& Green, 1970). The present results do not directly argue for a reconsideration of Seligman's (1970) proposal that exteroceptive events show a much lesser degree of associability with the internal events of nausea than do gustatory stimuli. The notion of preparedness is concerned with the relative associability of different classes of events, and states that associations of classes which can be established with a more "degraded input" are more prepared relative to associations between classes requiring a less "degraded input" to be formed. The concept of "degradedness of input" may be difficult to apply to the design of the present experiments. However, insofar as we have demonstrated that, given two conditioning trials, the background context of the conditioning trial is a necessary feature of the extinction trial environment for an aversion to be obtained, and that when the context is changed, there is evidence for an aversion only on the first extinction trial, it may be argued that, given the same amount of "input," the background context exerts a major part of the control over saccharin intake usually attributed to saccharin alone.

In the prepared learning theory (Seligman, 1970), there is a focus on acquisition as the defining operation for preparedness. In the present study, where it could be argued that extinction was chosen as an alternative defining operation (cf. Seligman \& Hager, 1972 , p. 5), data were obtained showing that the resistance to extinction of a saccharin aversion is highly dependent on the background context cues. Thus, the data permit the conclusion that one of the supposedly unique characteristics of taste-nausea associations, that is, their high resistance to extinction, is highly dependent on background context cues.

The background context of the present experiments consisted of a combination of visual, auditory, tactual, and olfactory cues. Thus, since olfactory cues differed between the experimentally defined contexts, the results cannot unequivocally be attributed to exteroceptive stimuli. It could be argued that the inclusion of a prominent odor cue may have altered the saccharin flavor in the "contextual" environment. Thus, saccharin in the presence of the odor could conceivably be sufficiently different from saccharin in the absence of the odor, resulting in a stimulus generalization decrement from conditioning to extinction in the $\mathrm{D}$ groups. Odor-toxicosis conditioning has been demonstrated in a number of studies (Domjan, 1973; Lorden, Kenfield, \& Braun, 1970; Taukulis, 1974; Taukulis \& Revusky, 1975). However, a recent study by Hankins, Rusiniak, and Garcia (1976) has indicated that odor cues are of little significance in poison-avoidance learning. Furthermore, these workers point out that some of the previous studies allegedly demonstrating odor aversions (e.g., Taukulis, 1974) failed to include anosmic control groups (but see Domjan, 1973; Larue, 1975). Also, when compound stimuli of taste and odor are presented, taste is the effective cue and 
odor is largely ignored (Nachman, Rauschenberger, \& Ashe, 1977, p. 113). However, it may be safest to conclude that odor may have contributed to a greater or smaller degree to the results obtained in the present study. It should also be noted that the size of the drinking nozzles differed between the contexts of the present study. Nachman et al. (1977, p. 116) have recently reported that this variable can be used to establish an aversion to a specific drinking bottle in the absence of a taste stimulus. Further work is required to assess the relative contribution of stimuli of different modalities to the observed effects.

\section{REFERENCES}

Best, P. J., Best, M. R., \& Mickley, G. A. Conditioned aversion to distinct environmental stimuli resulting from gastrointestinal distress. Joumal of Comparative and Physiological Psychology, 1973, 85, 250-257.

Domun, M. Role of ingestion in odor-toxicosis learning in the rat. Journal of Comparative and Physiological Psychology, 1973, 84, 507-521.

Domin, M., \& Wilson, N. E. Specificity of cue to consequence in aversion learning in the rat. Psychonomic Science, 1972, 26. 143-145.

Estes, W. K. Memory and conditioning. In F. J. McGuigan \& D. B. Lumsden (Eds.), Contemporary approaches to conditioning and learning. Washington, D.C: Winston, 1973.

Garcia, J., Kimeldorf, D. J., \& Hunt, E. L. The use of ionizing radiation as a motivating stimulus. Psychological Review, 1961, 68, 383-395.

Garcia, J., \& Koelling, R. A. Relation of cue to consequence in avoidance learning. Psychonomic Science, 1966, 4, 123-124.

Garcia, J., \& Koelling, R. A. A comparison of aversions induced by $\mathrm{X}$-rays, toxins, and drugs in the rat. Radiation Research Supplement, 1967, 7, 439-450.

Garcia, J., Kovner, R., \& Green, K. F. Cue properties vs. palatibility of flavors in avoidance learning. Psychonomic Science, 1970, 20, 313-314.

Garcia, J., McGowan, B. K., Ervin, F. R., \& Koelling, R. A. Cues: Their relative effectiveness as a function of the reinforcer. Science, 1968, 160, 794-795.

Garcia, J., McGowan, B. K., \& Green, K. F. Biological constraints on conditioning. In A. H. Black \& W. F. Prokasy (Eds.), Classical conditioning II: Current research and theory. New York: Appleton-Century-Crofts, 1972.

Green, K. F., Holmstrom, L. S., \& Wollman, M. A. Relation of cue to consequence in rats: Effect of recuperation from illness. Behavioral Biology, 1974, 10, 491-503.

Hankins, W. G., Rusiniak, K. W., \& Garcia, J. Dissociation of odor and taste in shock-avoidance learning. Behavioral Biology, 1976, 18, 345-358.

Kalat, J. W. Biological significance of food aversion learning. In N. W. Milgram, L. Krames, \& T. M. Alloway (Eds.), Food aversion learning. New York: Plenum Press, 1977.
KIRK, R. E. Experimental design: Procedures for the behavioral sciences. Belmont, Calif: Brooks/Cole, 1968.

LARSEN, J. D., \& HydE, T. S. A comparison of learned aversions to gustatory and exteroceptive cues in rats. Animal Learning \& Behavior, 1977, 5, 17-20.

LARUE, C. Comparison des effets de l'anosmie périphérique et de la bulbectomie sur la séquence alimentaire du rat. Journal de Physiologie (Paris), 1975, 70, 299-306.

Lorden, J. F., Kenfield, M., \& Braun, J. J. Response suppression to odors paired with toxicosis. Learning and Motivation, 1970, 1, 391-400.

Mitchell, D., Kirschbaum, E. H., \& Perry, R. L. Effects of neophobia and habituation on the poison-induced avoidance of exteroceptive stimuli in the rat. Journal of Experimental Psychol. ogy: Animal Behavior Processes, 1975, 104, 47-55.

Nachman, M., Rauschenberger, J., \& Ashe, J. H. Stimulus characteristics in food aversion learning. In N. W. Milgram, L. Krames, \& T. M. Alloway (Eds.), Food aversion learning. New York: Plenum Press, 1977.

Rescorla, R. A., \& Wagner, A. R. A theory of Pavlovian conditioning: Variations in the effectiveness of reinforcement and nonreinforcement. In A. H. Black \& W. F. Prokasy (Eds.), Classical conditioning II. Current research and theory. New York: Appleton-Century-Crofts, 1972.

REvUSKY, S. Learning as a general process with an emphasis on data from feeding experiments. In N. W. Milgram, L. Krames, \& T. M. Alloway (Eds.), Food aversion learning. New York: Plenum Press, 1977.

Revusky. S. H., \& Garcia, J. Learned associations over long delays. In G. H. Bower \& J. T. Spence (Eds.), The psychology of learning and motivation: Advances in research and theory (Vol. IV). New York: Academic Press, 1970.

RoziN, P. Central or peripheral mediation of learning with long CS-UCS intervals in the feeding system. Journal of Comparative and Physiological Psychology, 1969, 67, 421-429.

Rozin, P., \& Kalat, J. W. Specific hungers and poison avoidance as adaptive specializations of learning. Psychological Review, 1971, 78, 459-486.

Rozin, P., \& Kalat, J. W. Learning as a situation-specific adaptation. In M. E. P. Seligman \& J. L. Hager (Eds.), Biological boundaries of learning. New York: Appleton-Century-Crofts, 1972.

Rudy, J. W., Iwens, J., \& Best, P. J. Pairing novel exteroceptive cues and illness reduces illness-induced taste-aversions. Journal of Experimental Psychology: Animal Behavior Processes, 1977. 3, 14-25.

Rudy, J. W., Rosenberg, L., \& SANDell, J. H. Distuption of a taste familiarity effect by novel exteroceptive stimulation. Journal of Experimental Psychology: Animal Behavior Processes, 1977, 3, 26-36.

Seligman, M. E. P. On the generality of the laws of learning. Psychological Review, 1970, 77, 406-418.

Seligman, M. E. P., \& Hager, J. L. (Eds.). Biological boundaries of learning. New York: Appleton-Century-Crofts, 1972.

TAUKULIs, H. K. Odor aversions produced over long CS.US delays. Behavioral Biology, 1974, 10, 505-510.

TAukulis, H. K., \& Revusky, S. H. Odor as a conditioned inhibitor: Applicability of the Rescorla-Wagner model to feeding behavior. Learning and Motivation, 1975, 6, 11-27.

(Received for publication October 17, 1977; revision accepted March 29, 1978.) 